\title{
Tiranicidios de papel: Teatro y oposición al trujillato
}

\author{
Emilio J. Gallardo Saborido
}

Queda una tercera especie de tiranía, que, al parecer, merece más particularmente este nombre, y que corresponde al reinado absoluto. Esta tiranía no es otra que la monarquía absoluta, la cual, sin responsabilidad alguna y sólo en interés del señor, gobierna a súbditos que valen tanto o más que él sin consultar para nada los intereses particulares de los mismos. Este es un gobierno de violencia, porque no hay corazón libre que sufra con paciencia una autoridad semejante.

(Aristóteles, Politica VI, 8)

Aun no siendo una de las expresiones culturales emblemáticas del país, el teatro dominicano atravesó una aguda crisis durante la mayoría de la Era de Trujillo (1930-1961). Para hacernos una idea de la eficiencia de la censura instaurada contra los medios artísticos en 1942, basta citar un pasaje de uno de los intelectuales cercanos al régimen sobre los logros de la dramaturgia de este periodo:

El Generalísimo y Doctor Rafael Leonidas Trujillo Molina, Benefactor de la Patria y Padre de la Patria Nueva, creó el Teatro-Escuela por Decreto Número 3545 del 10 de mayo de 1946, pocos días después del resonante estreno en el teatro Olimpia de la comedia Falsa amistad, original de su ilustre esposa, Doña María Martínez de Trujillo, bajo la dirección del recordado maestro español Emilio Aparicio, primer director del Teatro-Escuela. (Lockward 60) 
El nepotismo característico del régimen abrumaba hasta a las tablas. Sin embargo, en los últimos años de la dictadura trujillista vemos cómo surgen un grupo de obras que se atreven a disentir y a apostar, siempre en clave, por otro orden. Se unen así al creciente movimiento opositor de los últimos años de la dictadura. Aunque en el pasado se habían llevado a cabo acciones con el fin de derrocar al tirano, como la invasión de Luperón por parte de exiliados en 1949, sería al final de esta etapa histórica cuando se intensificaran las protestas. Moya Pons resume estas tentativas, que irían desde la frustrada invasión de Constanza, Maimón y Estero Hondo en junio de 1959, hasta las conspiraciones entre los propios amigos del dictador y otros que habían sido funcionarios del gobierno y colaboradores cercanos (523-24). Precisamente, el encargado de dirigir al grupo de hombres que acabaría con la vida de Trujillo sería un amigo de la infancia, Juan Tomás Díaz. Contando con el apoyo de los Estados Unidos, lo tirotearon en la noche del 30 de mayo de 1961, cuando se dirigía a su "Hacienda Fundación," en San Cristóbal. En cualquier caso, la caída del régimen era de esperar por varios factores: el asesinato de las hermanas Mirabal en noviembre de 1960, cuyos esposos habían sido encarcelados por participar en la conspiración del 14 de junio, hizo reaccionar definitivamente a un importante sector de la población; por otro lado, el Gobierno se enfrentaba a una crisis internacional y económica provocada por las sanciones que la Organización de Estados Americanos (OEA) le había impuesto; $y$, finalmente, la oposición popular también crecía por los ataques que Trujillo había dirigido contra la Iglesia Católica por negarle el título de "Benefactor de la Iglesia." Puestas así las cosas, Veloz Maggiolo habla de ese conjunto de textos dramáticos que suponen una parte de la oposición intelectual al régimen:

No obstante, un año antes de la muerte de Trujillo comienza a surgir un teatro de hondas raíces políticas, encarnado en las piezas Espigas maduras, de Franklin Domínguez, Prometeo, de Héctor Incháustegui Cabral, y Creonte, de Marcio Veloz Maggiolo. Las tres piezas se escriben casi en un mismo periodo, y las tres plantean desde ángulos de vista muy diferentes el problema político que atravesaba la República Dominicana. Desde luego todas usaban el símbolo y las tres tenían como tema la quiebra del poder. Dos de ellas, Prometeo y Espigas maduras, fueron llevadas a las tablas, y la tercera vio la luz también en forma de publicación en 1960. (Cultura, 187-88)

Con este artículo pretendemos enfrentarnos al abrumador vacío crítico que se cierne sobre la historia del teatro dominicano y que recientes 
publicaciones, como las del profesor L. Howard Quackenbush, ${ }^{1}$ se esfuerzan por superar. Tiraremos del hilo propuesto por Veloz Maggiolo, quien vincula un tipo de teatro a la resistencia política contra el trujillato. Analizaremos esos "ángulos de vista muy diferentes" a través de los que se enfrentan al poder, subrayando cómo entre las potencialidades del hecho escénico se encuentra la de actuar de revulsivo en los momentos de crisis política.

\section{Desbrozando el conuco patrio: "Espigas maduras"}

En Espigas maduras (1958, estrenada en 1960), de Franklin Domínguez, se hace uso del drama familiar, localizado y particular, para representar el conflicto nacional que el autoritarismo dictatorial había provocado en el conjunto del país. El costumbrismo ambiental de la pieza (la acción tiene lugar en un "rústico caserón campestre"), que elige como punto focal de las tensiones la vivienda familiar, juega un papel subversivo en el sentido de que potencia la lectura simbólica del drama. De este modo, al no darse marcas precisas de localización espacial, se invita al lector/espectador a generalizar la situación presentada. Veloz Maggiolo considera evidente la presencia en la obra del símil padre/Trujillo; es más, cree que el texto se ha de vincular con los acontecimientos que dieron origen al Movimiento Revolucionario 14 de junio, que culminaría con numerosas víctimas y presos políticos (Cultura, 188).

Del dramaturgo, el Diccionario de autores dominicanos (14922003) de Cándido Gerón nos dice:

Nacido el 5 de junio de 1931 en Santiago de los Caballeros. Como político se inicia durante el régimen de Trujillo, cuando escribe y lanza manifiestos clandestinos, principalmente aquel que pide un homenaje a las hermanas Mirabal en febrero de 1961. Ya anteriormente, en 1959, critica riesgosa y abiertamente a Trujillo en su afamada obra Espigas maduras. En 1961 dirige en Puerto Rico el periódico de la Unión Revolucionaria de Exiliados Dominicanos (URED), que orientaba Juan Isidro Jimenes Grullón. Fue condecorado por el Presidente Balaguer con la Orden de Cristóbal Colón en el grado de Caballero; en 1997, condecorado con la Orden del Mérito de Duarte, Sánchez y Mella, en el Grado de Comendador, por el Presidente Leonel Fernández, por sus cincuenta años de labor artística. La política brota en la mayoría de su teatro integrado por más de 70 obras escritas y representadas internacionalmente. OBRA: El último instante, 1962 (En Teatro hispanoamericano, antología). 
Se busca un hombre honesto, 1965. Teatro: Espigas maduras, Antígona-humor, Los actores, El encuentro, 1968. Lisístrata odia la política, 1981. (84-85)

En cuanto a la acción, se estructura externamente en tres actos, sin una división explícita en escenas. El primer acto arranca con la llegada a la casa de los hermanos Alejandro y Danilo, quienes vienen de trabajar. Mientras desayunan mantienen una conversación en la que se evidencian sus diferentes posturas ante la obediencia debida al padre, de quien se resalta su prosperidad, abnegación, pero también la codicia. Junto a su hermana Matilde tratan sobre el temor de que el padre castigue severamente al hermano menor, Joaquín, por haber desobedecido la orden paterna de no ir a la fiesta de la noche anterior. Al poco, Matilde les comunica su intención de casarse con Manuel, un campesino vecino. La conversación queda interrumpida de súbito al entrar Sebastián, el padre, a quien le enerva el componente de desobediencia que ve en la escapada de Joaquín. Ante los intentos de defensa por parte de los otros hermanos, Sebastián insiste en lo que considera sus defectos (haragán, lector, rebelde) y lo manda a llamar. Al quedar solos Sebastián y Danilo, éste le recuerda su promesa de separar los bienes, mientras que su padre enfatiza lo provechoso de mantenerse unidos, situación que espera perpetuar hasta su muerte. Sin embargo, Danilo le aclara que la mitad de los bienes adquiridos durante el matrimonio le correspondería a su madre, quien los dejó a sus hijos al morir. Al poco llega Joaquín, un poco embriagado. Se opone frontalmente al padre, quien amenaza con azotarlo. Pero, antes de que pueda hacerlo, Matilde consigue detenerlo diciendo que, si arremete contra su hermano, contará la verdad sobre la muerte de su madre.

El acto segundo comienza a la hora de almorzar. Joaquín le expone a Matilde su punto de vista sobre la posesión de la tierra: la ve de una forma mucho más idealista, sentimental, y aborrece la explotación a la que la somete su padre. Del mismo modo, defiende la independencia que los hijos merecen respecto a su padre, y confiesa haberla logrado al acudir a la fiesta. Así pues, invita a Danilo y Matilde a que se sacudan el yugo paterno. Sin embargo, y haciendo un símil político, si Joaquín defiende una posición revolucionaria, Danilo y Matilde apoyarían más bien una transición pausada. Y aunque seguidamente Matilde le comunicará a su padre la intención de casarse con Manuel, acabará dando marcha atrás ante sus amenazas.

El último acto arranca a la hora de la cena. Sebastián comunica a sus hijos que ha comprado nuevas tierras, por lo que tiene que enviar a uno de ellos a cuidarlas; finalmente se decide por Alejandro. Una vez que 
Sebastián se marcha, se confronta el discurso de la sumisión de Alejandro y el de la independencia de Joaquín. Por otro lado, se nos hace saber que Danilo fue golpeado salvajemente por su padre en una ocasión en la que intentó escapar. Enlazando con este asunto, Matilde, antes de huir con su prometido, confiesa la verdad sobre la muerte de su madre: impotente ante la paliza que Sebastián le propinaba a Danilo, se suicidó. Los varones coinciden en que es necesario vengarse de su padre, lo cual harán si se vuelve a negar a hacer la partición. El encargado de ejecutarla será Alejandro. Cuando llega, Sebastián mantiene su postura sobre la separación de las propiedades. Ante esto, los hermanos le comunican la marcha de Matilde y cómo son conscientes de por qué murió su madre. Finalmente, Alejandro, al ir a asesinarlo, descubre que Sebastián sólo es un cobarde, por lo que deciden dejarlo con vida, pero solo. El final de la obra constituye un momento de gran patetismo: Sebastián grita desesperadamente los nombres de sus hijos varones, quienes lo acaban de abandonar.

Como decíamos, la oposición espacial a la autoridad paternodictatorial se concreta y concentra en la misma casa familiar. El uso de sus estructuras y la distribución de las mismas son aprovechadas por Domínguez para reflejar las tensiones familiares-nacionales. Gaston Bachelard había hecho referencia en el capítulo de La poética del espacio dedicado a "La casa. Del sótano a la guardilla. El sentido de la choza" a los dos valores positivos de la residencia natal: el sueño y la protección. Según su punto de vista, esta edificación funcionaría como una gran cuna, donde el soñador se siente seguro, incluso cuando sólo vuelve a ella a través de la memoria. Sin embargo, Bachelard obvió otro matiz en su topoanálisis: la casa natal como síntesis de la pesadilla, como cónclave de los fantasmas y sus cadenas. En este caso, los traumas desarrollados en ese ámbito invitan a escapar, a renegar de él y sus dueños (33-69).

Cuando se analiza el valor simbólico de una vivienda es importante conocer por dónde se abre al mundo, cómo se comunica con el exterior. La entrada principal de la vivienda de la familia, que escénicamente queda fuera de la visión del espectador, representa el lugar de paso "digno," que transitan los varones cuando van o vienen del trabajo. Además la zona colindante de la fachada puede ser utilizada para recrearse discretamente, como hace Alejandro al tocar allí la armónica, una vez que ha concluido las tareas del campo. Es sintomático que el único de los hermanos que disfruta tocando un instrumento musical sea el mayor, el que secunda en mayor grado la autoridad paterna. De hecho, en el texto se indica explícitamente el rechazo de los 
otros hermanos a la tranquilidad y pasividad que el primogénito demuestra al tocar la armónica incluso en momentos críticos:

DANILO (volviendo junto a la puerta): Escucha, Matilde. Alejandro está tocando su armónica. Le encontré ahí fuera, me dio la queja de papá y siguió tocando su armónica alegremente. (Ríe). No sé cómo todavía puede tocar alegremente su armónica. (Ríe, mientras vuelve junto a la escalera). Papá, baja, ya estoy aquí. Me retrasé, pero ya estoy aquí, siempre a tus órdenes. (66)

No es ningún secreto que en las sociedades rurales occidentales el periodo de luto conlleva(ba) una represión de cualquier manifestación musical en la intimidad del hogar (los cantos fúnebres, como el gorigori de García Lorca, quedaban reservados para otros espacios de plañimiento colectivo, como la iglesia, el cementerio o el camino que los une). Cuando se está triste no se canta; es una máxima en estos casos. Si bien en la obra no hay una referencia explícita a que la familia aún esté guardando el luto por la muerte de la madre, se puede entender que ese periodo se ha extendido ilimitadamente al desaparecer el contrapeso materno que suavizaba los desmanes del padre. Además, el despotismo patriarcal ha convertido a sus hijos en muertos en vida, en zombis alienados por el trabajo y la obediencia debida.

A esa entrada reconocida, privilegiada, se oponen otros medios a través de los que escapar de la casa y de la autoridad falocéntrica. Ligados siempre a la complicidad de la noche, constituyen modos espurios de comunicación con el exterior, recursos de los oprimidos para "vivirse" fuera, métodos de resistencia a la autoridad. En concreto, nos referimos a las ventanas y a la puerta de atrás. Una de las formas de resistencia ante los abusos del padre es el amor; éste se consigue a través de esos dos huecos por los que se quiebra la autoridad. Joaquín se lamenta de que Danilo haya tenido que estar utilizando las ventanas para visitar a su amada: "Es vergonzoso que un hombre tenga que escapar de su casa por la ventana porque tiene miedo a que descubran que usa la puerta para salir" (41). Por su parte, los encuentros de Matilde con Manuel se producen habitualmente en "la puerta de atrás, cada noche" (53). La represión que tiene soportar Matilde es aún mayor si cabe, dada su condición de mujer. La discriminación de género la ata a la casa, en particular a la cocina. Para ella la vivienda no es sólo morada y cárcel, sino también centro laboral. Teresa del Valle al tratar de los cierres domésticos apunta:

El espacio interior-doméstico evoca contenidos que se relacionan con movimientos espirales, con el mundo interior. Las asociaciones 
que se hacen de la mujer con relación al espacio interior expresan que ella ocupa un lugar central desde donde ejerce e irradia influencia a través de las actividades que realiza y de las responsabilidades que asume; es un lugar donde está a la espera de otros y desde donde refuerza la importancia que tienen las actividades y los roles que se ejercen en los otros espacios. (183-84)

La comparación de la obra de Domínguez con La casa de Bernarda Alba de García Lorca nos ayuda a comprender el sentido de la clausura impuesta por el padre, el de la impotencia de habitar una casa sellada y sometida al cronometraje de los horarios de trabajo y expansión. En ese sentido, Del Valle incide en que: "En la casa de Bernarda se han establecido límites reales, como puertas, ventanas, cortinas, paredes, vallas, y cierres simbólicos a través de ellos mediante mecanismos de lenguaje, alturas y colores" (184). Por todo ello, cuando los hijos logran superar la castración que les imponía Sebastián, Danilo puede alegrarse al decir: "Ahora no tendré que escapar por las ventanas, papá. Podré usar la puerta" (77).

Sin embargo, el tiempo de ocio tolerado por el padre suele aprovecharse en el salón familiar, siguiendo esa tendencia introspectiva y egoísta que lo ha llevado a atomizar su posición dentro de la comunidad, rompiendo las relaciones con el resto de los vecinos. Esta quiebra se ha producido, en primer lugar, entre sus iguales ("tus vecinos se han convertido en rivales a quienes quieres superar y hundir," 53), de cuya desgracia no duda en aprovecharse, como demuestra al adquirir las "tierras del norte." Eugenio, su propietario, al que parece conocer desde varios años, se había visto avocado a deshacerse de ellas para poder hacer frente al préstamo que el mismo Sebastián le concedió con el fin de explotar los terrenos. Su codicia usurera cierra así un círculo que acaba convirtiéndolo en un poderoso terrateniente. Claro que su creciente prosperidad económica ha tenido que recurrir a otros mecanismos para desarrollarse. Así, la segunda ruptura social enfrenta a Sebastián con sus subordinados, con sus asalariados. Domínguez aprovecha aquí para criticar la precaria situación de los peones que realizan trabajos estacionales en el campo, teniendo que afrontar la penuria de los "tiempos muertos," en los que no trabajan. El padre muestra ahora la cara más amarga de un capitalismo salvaje, que tiene bien claro que salvaguardar los propios intereses está más allá de la mejora de las condiciones de las masas campesinas, quienes no obstante posibilitan en gran parte ese enriquecimiento: 
SEBASTIÁN (levantándose y acercándose a Matilde): Yo no puedo solucionar el desempleo. Contrato y pago. Si este año traen los mismos problemas, ya aparecerán otros hombres para realizar el trabajo. Peor para los que se quejen y quieran reclamar más de lo convenido. (50)

Pero el proceso que sigue Sebastián no sólo lo lleva a distanciarse de sus iguales e inferiores, sino que se proyecta de forma ascendente, aspirando a equipararse a las clases dominantes. Teniendo en cuenta que el drama se inserta en una sociedad histórica donde el aparentar era una de las preocupaciones esenciales de los poderosos, donde el que tiene se esfuerza por diferenciarse de los desposeídos, se entiende que Sebastián pretenda medrar a través de las mejoras de sus "posesiones." En efecto, la obra casi arranca con unas palabras de Alejandro que recuerdan la intención del padre de querer mudarse a una casa mejor. Pero como Matilde también se encuentra entre las riquezas de su padre, se ve sometida a ese proceso de "ennoblecimiento." De modo que, al enterarse de que ella pretende desposarse con Manuel, un campesino, Sebastián se opone decididamente argumentando que no es digno mezclarse con los trabajadores. Ante lo que Matilde se ve obligada a contestarle que, por culpa de su excesivo celo, que hizo que dejara de asistir a la escuela, ella no tiene la preparación ni el perfil para convertirse en "una señorita de la ciudad."

Ese salón familiar al que antes nos referíamos incumple la supuesta función de espacio de encuentro y charla que virtualmente tiene asignado. La incomunicación se hace allí más patente. La misma estructura de la obra refuerza esta idea puesto que los tres actos giran en torno a las horas en las que la familia se reúne para tomar desayuno, almuerzo y cena. Allí descubrimos que las relaciones entre padres e hijos han transcurrido entre el silencio y la orden, que es como el poder dictatorial se suele relacionar con sus súbditos. Cuando Matilde acude a su padre para contarle que pretende casarse, se ve obligada a reconocer que se encuentra ante casi un desconocido:

SEBASTIÁN: Es extraño. Nunca hemos hablado tú y yo de cosas que necesiten decirse especialmente.

MATILDE: No hemos conversado muy a menudo. (50)

En el primer acto nos enteramos de que Joaquín había salido la noche anterior, tras lo que había regresado borracho, por primera vez en su vida. Matilde le confiesa a su padre que ve a su hermano extraño desde hace algunos días, por lo que le aconseja que le pregunte qué le pasa. Sebastián reconoce que nunca le ha preguntado nada (32), y no está dispuesto a cambiar 
su forma de "educar" a sus hijos ("es a fuerza de látigo como se doma a los potros salvajes," 74). Por ello, en vez de por el diálogo opta por el insulto y la represión. Se instaura así un orden casi militar bajo el que se rigen las relaciones paterno-filiales, y que se expresa tanto en las voces (de mando), dirigidas a los campesinos y a sus hijos, como en referencias explícitas:

JOAQUÍN: ¡Este no es el ejército!

SEBASTIÁN: Pero es mi casa y quiero orden. (57)

Además ese salón también es foco de tensiones simbólicas como vemos al atender a los juegos con los que cada uno de los integrantes de la familia se distraen. En primer lugar, los varones se dedican a los juegos de azar, pero no todos al mismo. El padre prefiere una distracción mucho más mecánica e individual como es el solitario, que denota su naturaleza taciturna y egoísta, a la par que su aislamiento. Mientras tanto los hermanos prefieren el dominó, un juego colectivo, donde la estrategia cumple un importante papel. El dominó deviene así en una representación paralela de la situación real: tantear a los oponentes del juego es lo que están haciendo unos con los otros, calibrando sus fuerzas y sus posturas ante el padre. Comentaba Huizinga en su Homo ludens: "Desde que existen palabras para designar la lucha y para designar el juego, fácilmente se ha denominado juego a la lucha" (117).

Los entretenimientos a los que, presumiblemente, se dedica Matilde, quien durante esos momentos suele aprovechar para encontrarse con Manuel, son de otro signo. La mujer se puede ver desposeída, humillada, esclavizada, pero siempre conserva un arma con el que destruir al hombre de estas sociedades falocéntricas: el sexo. Aunque ello le puede acarrear una represión mayor, también le sirve de instrumento para "manchar la honra" del guardián masculino de turno, quien al vigilar la pureza femenina guarda la propia consideración que le han de mostrar los otros miembros de la comunidad. Por eso, cuando Sebastián se entera de que su hija se ha fugado con su novio, exclama colérico: "Nadie se burlará de mí" (76).

Como veíamos, los hombres viven preferentemente de la casa para fuera y la mujer, Matilde, de la casa para adentro. Pero los espacios de acción de los primeros quedan limitados a los meramente laborales, incluso cuando acuden a la ciudad lo hacen para desempeñar cualquier tarea, para ejecutar cualquier orden paterna. Los lugares de esparcimiento social (la taberna, el lupanar, la calle) les están vedados a los hermanos. Por ello, el enfrentamiento con el padre representa además una reivindicación por administrar su propio ocio. Y no sólo en el plano espacial, sino también en el temporal. La temporalidad que impone Sebastián a sus hijos se ajusta a los 
horarios laborales, pero va más allá y se adecua a sus caprichos personales, a sus ansias de control exclusivo sobre su prole, que queda así reificada, mercantilizada como las tierras o el ganado. Es más, los tres hermanos pasan a formar parte del engranaje casi mecánico con el que su padre pretende aumentar sus ganancias ad infinitum: "a tu lado me siento como un autómata" (27); "no quiero ser una pieza más de una máquina que quiere abarcarlo todo," confiesa Danilo. Y no sabemos hasta qué punto sus hijos representan su más valiosa posesión, pues viendo el celo con el que Sebastián cuida a su yegua blanca, preñada, "se diría que la quiere más que a sus hijos," según opina Danilo (18).

Sebastián opta por una temporalidad de industria para sus hijos y para él mismo, donde hay que "fichar," y donde los ratos de esparcimiento se encuentran regulados y determinados por las horas de trabajo: "Pasan todo el día en el campo y sólo vienen a la casa a las horas de comer y dormir. ¡Nunca una diversión! Y cuando podemos conversar, todos estamos cansados," afirma Matilde (20). Así pues, la oposición de Joaquín también se centra en un enfrentamiento cronológico y, cuando su padre le acusa de haberse despertado demasiado tarde, él le puede contestar que no le importa (32). Sin embargo, el tiempo también se puede volver del lado de los oprimidos, cuando estos deciden rebelarse y concentrar la revuelta en un mismo día, que es el tiempo interno de la representación. El "hoy" en el que Matilde promete decirle a su padre que se desposará con Manuel fecha la sublimación de los traumas de los hermanos al enfrentarse directamente a su padre (22).

No obstante, la oposición al orden de respeto y temor que propugna el padre no es desde un principio unánime. Más bien, a lo largo de la pieza las posiciones de los cuatro hermanos van evolucionando hasta alcanzar el consenso y el rechazo final. Pero en un primer momento las posturas oscilan entre la rebeldía clara del menor, de Joaquín, y el conformismo del mayor, Alejandro: entre el " $j$ es necesario vivir y si no se puede vivir se impone la muerte!" (63), y el "es imposible oponernos a su voluntad" (62). La situación de las tensiones entre padre e hijos patente al final del tercer acto se puede reflejar gráficamente acudiendo a las herramientas de la semiótica actancial. De este modo, obtendríamos: 


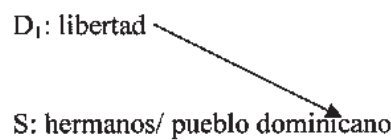

O: independencia económica, sentimental/ política

A: suicidio de la madre, Manuel, herencia, alcohol, sexo, etc.
$\mathrm{D}_{2}: \operatorname{los}$ mismos sujetos

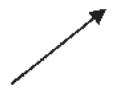

Op: Sebastián/dictador

(respeto y temor), resistencia

inicial de Alejandro y, en parte, de Danilo.

Donde: $\mathrm{D}_{1}$ representa al destinador, o aquel elemento que justifica causalmente la acción del sujeto; $\mathrm{D}_{2}$, al destinatario, la finalidad de dicha acción; $\mathrm{S}$ es el sujeto y $\mathrm{O}$, su objeto; A aglutina a los ayudantes, mientras que Op hace lo propio con los oponentes. Ubersfeld matiza el modelo que ofreció Greimas, donde las flechas de los ayudantes y los oponentes apuntan hacia el sujeto, en vez de al objeto. Justifica esta decisión porque prefiere "hacerlas desembocar en el objeto, en la medida en que el conflicto ocurre en torno al objeto" (50). Como se puede apreciar, el modelo de la obra ofrece una doble lectura que desenmascara la relación entre el conflicto familiar y el nacional. Así, el drama evoca simbólicamente la claustrofobia experimentada por los oprimidos durante el régimen de Trujillo. El recurso a la figura paterna como trasunto del dictador es todo un tópico literario con raíces tan milenarias como el Edipo rey de Sófocles, y que en la dramaturgia caribeña alcanzó su momento cumbre con La noche de los asesinos (Premio Casa de las Américas, 1965), del cubano José Triana.

Como oponente, Sebastián cuenta con una serie de elementos materiales que codifican su poder (zapatillas/dominación doméstica, lodo/ vinculación a la tierra, dinero/poder económico), siendo uno de los más significativos el fuete, objeto de represión de los escasos intentos de liberación de Danilo y Joaquín. Este látigo encuentra un correlato en el rebenque del Don Zoilo de otro drama rural, el clásico de Florencio Sánchez Barranca abajo (estrenada en 1905). Ambos personajes representan un orden patriarcal que toca a su fin, aunque en el caso de Don Zoilo, resabio gaucho, las simpatías del autor caen del lado del protagonista. La derrota pasa por encima de ambos; no obstante, el suicidio de Don Zoilo al final de la obra nos muestra un hombre deshecho por las intrigas de parientes y extraños, avenidos por la codicia y el egoísmo, aunque sin llegar a la idealización. En cambio, con la 
soledad final a la que se ve avocado Sebastián, Domínguez otorga el que cree justo merecido de un tirano que no ha sido capaz de ceder ni un ápice de su poder.

Sin embargo, existe otra serie de objetos y símbolos que codifican un contraorden latente, que se manifiesta a través de varios modos de liberación. Una primera forma de escapar del control totalitario-patriarcal la otorgan los métodos puntuales. La exaltación de lo dionisiaco que se encuentra en determinados pasajes del drama, donde se recomienda el uso del alcohol ("DANILO: El alcohol nos impide pensar es lo que necesitamos," 43) o del sexo como medios de evasión. Como es de esperar en una sociedad rural, la diversión se encuentra ritualizada. En este caso, las distintas alusiones al baile como espacio de sociabilidad y esparcimiento regulado al que, sin embargo, se impide asistir constantemente a los hermanos, muestran otra evidencia del aislamiento familiar.

Las lecturas de Joaquín, tan recriminadas por Sebastián ("Evita el trabajo y viene a encerrarse con sus malditos libros en la habitación," 25), ayudan a fraguar uno de los dos modos de liberación definitivos: la ruptura violenta con el régimen imperante. El símbolo climático de este proceso sería el cuchillo con el que se amenaza de muerte a Sebastián. Tánatos/eros forman una pareja opuesta, pero que en este contexto buscan el mismo fin: la liberación. De este modo, la huida por amor de Danilo, los esponsales entre Matilde y Manuel, constituyen otra forma de desprecio de la autoridad. En ambos casos se trata de un proceso de negación constructiva, que busca desterrar un orden subyugante para instaurar una nueva escena que permita moverse a los individuos autónomamente.

Para concluir con este apartado, desearíamos volver a insistir en el triple paralelismo que hace de Espigas maduras un artefacto subversivo, políticamente hablando: Trujillo/Sebastián, casa rural/ República Dominicana, hijos/ pueblo dominicano. Domínguez adapta al medio rural dominicano la tradición de "analizar la familia pequeño-burguesa como un microcosmos nacional, y a partir de sus conflictos establecer la agonía y frustraciones de la sociedad" (Leal VII), que en Cuba había inaugurado José Antonio Ramos (1885-1946).

\section{La tragedia que no cesa: (re/de)construyendo el agon clásico}

El otro medio formal que utilizan las obras mencionadas por Veloz Maggiolo para reclamar un cambio político se basa en la actualización o reescritura de temas del teatro griego clásico. En esa línea se inserta Prometeo, 
de Incháustegui Cabral. Primera de las tres obras de la trilogía Miedo en un puñado de polvo (junto con Filoctetes ${ }^{2}$ e Hipólito), Prometeo revisa el tema clásico de Esquilo y lo adapta a la contemporaneidad dominicana, haciendo del protagonista un hijo desencantado con su propio padre, poderoso empresario contra el que trata de rebelarse en vano. La pieza sería llevada a las tablas, y publicada en Buenos Aires en 1964, junto con los otros dos componentes de la trilogía. Gerón hace la siguiente semblanza de su autor, Héctor Santiago Incháustegui Cabral:

Nació en Baní el 25 de julio de 1912. Falleció en Santo Domingo en septiembre de 1979. Poeta, escritor y educador. Fue jefe de redacción, editorialista y articulista del Listín Diario, al igual en La Nación. Dirigió La Opinión. Formó parte del grupo que dirigió y estableció los Cuadernos Dominicanos de Cultura de 1943 a 1952. Ejerció funciones diplomáticas en Cuba, fue Embajador en México, Venezuela, Ecuador, El Salvador y Brasil. Como escritor obtuvo en 1952 el Premio Nacional de Literatura "Pedro Enríquez Ureña". (Gerón 135)

La rebelión de Prometeo completa la de los hijos de Espigas maduras en dos sentidos: en primer lugar, la acción se traslada del campo a la ciudad, y, en segundo lugar, el poder es enfrentado desde la propia alta burguesía con la que guarda estrechos lazos. De este modo, vemos cómo al calibrar conjuntamente los mensajes políticos de las dos obras se conforma un panorama de resistencia al que están llamados a jugar un papel esencial tanto el campesinado, mejor o peor avenido, como la burguesía (no olvidemos la procedencia social de elementos tan decisivos en la lucha anti-trujillista como las hermanas Mirabal).

No obstante, quisiéramos dedicar las páginas que restan a profundizar en el Creonte de Veloz Maggiolo. Hombre polifacético (además de dramaturgo es novelista, arqueólogo y crítico literario), este autor nació en Santo Domingo el 23 de agosto de $1936 .^{3}$ A través de la revisión de la Antígona de Sófocles, y centrándose en la figura de Creonte vuelve a proyectar esa especie de rebelión anti-saturnal que hace que la caída del padre venga apoyada por los esfuerzos de sus propios hijos (o familiares), incapaces de seguir bajo su dictadura. Por cierto, el propio Sófocles conoció la opresión tiránica de la mano de los Pisistrátidas (los hemanos Hiparco e Hipias). Así pues, el drama arranca tras la derrota de los argivos en el asalto a las siete puertas de Tebas. Una vez muertos los respectivos jefes, Etéocles y Polinices, su pariente Creonte se ha alzado con el poder en la ciudad. Lleno 
de soberbia, éste se resiste a sepultar los cadáveres de los vencidos y, lo que es aún peor, de Polinices, quien había conducido al ejército extranjero hasta allí. De aquí arranca la subtrama que enlaza con el tema clásico y a través de la que se nos narra la tragedia de Antígona, hermana de Polinices, y de su joven prometido, Hemón, hijo de Creonte. La tragedia de Veloz destapa la impiedad del tirano repitiendo el motivo clásico: no querer sepultar a los caídos constituye una severa ofensa religiosa. Sin embargo, nuestro autor no sitúa el foco de la acción en ese conjunto de personajes, sino que añade nuevos actores a la trama de la versión sofóclea, que ahora pasan a ocupar los roles de protagonistas. Por lo pronto, nos conduce fuera de la ciudad, a un paisaje de "aspecto desolador," desértico, donde sólo se divisan rocas y árboles mustios, y que preludia la destrucción que está por venir. Allí, a una relativa escasa distancia de las murallas de Tebas, nos encontramos con un grupo de hombres deshechos y sucios. Se trata de Adarco, capitán argivo, y dos de sus jóvenes soldados. Los tres huyen tras la derrota sufrida por su ejército. Más adelante se les unirá un Anciano, quien introduce el elemento profético en escena. En efecto, tras habérsele aparecido su hijo insepulto (Anarquides), caído en la batalla, y después de saberse apoyado por las fuerzas de Apolo, ha decidido peregrinar hasta Tebas con el fin de ofrecer a su hijo los ritos fúnebres oportunos. Por cierto, no olvidemos la especial vinculación de aquella deidad con la creación artística. De este modo, se entronca el poder de lo divino en el drama, con el de las artes en el contexto histórico real, enalteciendo así su fuerza como agente del cambio político. Añadamos que a estas alturas de la obra, un Tebano ha entrado oportunamente en escena, comunicando a los presentes la ascensión de Creonte y su irresponsable endiosamiento. Y aunque la misión del Anciano no va tan encaminada a destruir el régimen de Creonte, como a salvar a su hijo, no dudará en acabar con el rey tebano si se opone a su meta. Sin embargo, confiesa que todo ha de transcurrir sin violencia militar, puesto que así obedecerá a los designios del dios.

En cambio, la opción por la que apuesta el hijo rebelado, Hemón, quien hace su aparición en la escena VI (según nuestra división de la obra), es claramente bélica: intenta convencer a los argivos para que vuelvan a combatir, contra Creonte esta vez, para que lo ayuden a subir al poder para instaurar lo que promete que será un orden de paz y justicia. A Hemón lo mueven estos objetivos, pero también su pasión amorosa: el temor por la vida de Antígona. Todo ello hace que esté dispuesto a que se cometa un nuevo derramamiento de sangre. El Anciano, quien ha ido convenciendo progresivamente a Adarco y los suyos, se reafirma en su posición de cómo 
ha de transcurrir todo, y se subordina a Apolo hasta el punto de llegar a aceptar la muerte de Antígona "si Apolo así la manda" (27). Y todo ello porque él no está ofreciendo un nuevo enfrentamiento al uso, sino la fuerza de la esperanza. Este modo de actuar se plasma en las llamadas que el Anciano hace a la "espera." El acto de esperar se vincula a la esperanza misma, asumiendo que los acontecimientos no se han de forzar, sino que se ha de aguardar hasta su madurez ("Todo tiene su tiempo de espera, porque esperar es semilla de vida, almendra de toda perspectiva humana," 37 ). Finalmente, Hemón se acabará plegando al mensaje del Anciano, consintiendo en pasar por doble traidor (ante Antígona y ante su padre), mas no por impío, abandonando así sus proyectos de sublevación.

Hasta ahora los acontecimientos principales que iban dinamizando la acción del poder establecido nos eran comunicados por la utilización de distintos mensajeros que iban y venían a la ciudad (Tebano, algún soldado); sin embargo, a mediados de la obra, hace su aparición el propio Creonte, quien a lo largo de las siguientes escenas pasará de su porte altanero y su "risa violenta" (39) a su posterior "risa quebrada" (72), enloquecida, del final de la obra. En efecto, con el transcurrir de la obra las desgracias empezarán a cercarlo, al igual que los argivos hicieran con Tebas, pero en este caso su estabilidad emocional no tendrá el temple para soportar el asedio, cayendo irremisiblemente tras conocer las muertes de su hijo y su esposa (Eurípides), y temiendo que los males se extiendan a Althea, su hija. Así, destruidas su soberbia y altanería, dará permiso finalmente para que se abran las puertas y para que se cumplan los requisitos del dios, al que suplica detenga sus desgracias. El patetismo de su último parlamento, entremezclado con su grotesca risa, nos da la imagen de un Creonte deshecho, quien al gritar " $i L o$ ordena Creonte, rey de Tebas!" (72), parece que lo hace desde la posición del bufón que juega a ser emperador, de aquel que sabe que su poder vale mucho menos que el polvo en el que se convertirán los cadáveres de sus enemigos.

Aunque el conflicto más perentorio reside en las tensiones entre un poder mundano que osa enfrentarse a los designios de la divinidad, el mensaje de la obra se extiende a través de la certeza que nos transmite el Anciano en cuanto a la proximidad del fin de la tiranía: tan sólo hay que esperar. Así lo ha reconocido el propio autor, trasladando la acción dramática al contexto histórico de la República Dominicana del fin del trujillismo:

Creonte, cuyo tema se extrae de la tragedia Antígona, de Sófocles, tiene los símiles de aquel momento en que la dictadura de Trujillo se 
enfrentaba al poder religioso en $1960 .{ }^{5}$ Pero en el fondo no es otra cosa que una predicción del derrumbe de la dictadura. (Veloz Maggiolo 188)

Por supuesto, el asunto básico es el que Reyes ha calificado como "el gran tema dentro del teatro dominicano actual: el poder fuerte, el alto poder y la rebelión que forma su contraparte en toda la sociedad humana" (1972: 85-86). En efecto, siguiendo la retórica clásica, Creonte puede ser calificado como un adikón, como aquel que "sin verse obligado, ha optado deliberadamente por cometer un delito" (Pavis 231). No obstante, no podemos decir que Creonte, al elegir no dar marcha atrás en su decisión de dejar insepultos a los cadáveres, obrara presumiéndole una total libertad, dado que se encontraba en el dilema de mostrarse o débil o impío ante su pueblo. Sin embargo, una vez tomada la decisión errónea, Creonte se reafirma en su hybris, llegando al extremo sacrílego de querer cambiar la tradición religiosa, pasando de un vínculo humanidad-divinidad basado en la subordinación a otro apoyado en la volición humana, y aspirando a ser elevado a la categoría de nuevo dios. Todo esto se puede apreciar claramente en los siguientes parlamentos del tirano:

¿Quiero que ellos [los dioses] sean mis cómplices, quiero borrar la tradición de que el dios sólo obra a favor de quien le obedece! El dios es sensible y admira, y yo seré el primero que oponiéndose a sus mandatos sentirá sobre sus espaldas el fino manto de sus reconocimientos y la verdadera riqueza de la tierra! (41)

¿Quebrar mi santa palabra, mi divina palabra, mi palabra de dios? ¿Y qué dirá mi pueblo, y qué dirán los míos cuando vean a su rey forzado a violar sus decretos por unos descamisados? (55)

De hecho, a lo largo de la obra se produce un paulatino proceso de desencanto del pueblo con Creonte, que acaba conduciendo a una franco rechazo. Así la confianza de la sociedad tebana en Creonte se va resquebrajando paso a paso. Paradójicamente, la caída del tirano tiene su origen en su deseo por mostrarse seguro, inflexible en sus órdenes, para que sus súbditos lo respeten. Sin embargo, estos se muestran cada vez más alterados por la impiedad de su rey, que lo ha llevado a la muerte de la propia Antígona, entre otras transgresiones religiosas. Informa el Soldado Segundo: "[La ciudad] Comenta por igual, que estás maldito de los dioses porque dejaste exento de ritos y libaciones el cadáver de tu sobrino, y condenas a muerte a la novia de tu hijo por querer darle paz a tu propia sangre" (63). 
La comunicación rey-pueblo ha quedado rota, al igual que ha pasado con la relación de Creonte con lo divino. Así, cuando el Anciano le niega a Creonte la capacidad de gobernar sobre los muertos (46), éste parece que no entiende a qué se refiere. Hay una ruptura dialogal puesto que su obsesión por el poder lo remite al qué hacer con los cadáveres de los caídos, a los que no se cansa de denostar ("un montón de carne putrefacta," "basura," 46). El tirano pretende demostrar que sus manos y su lengua tienen la capacidad suficiente como para atar y deshacer los designios de la carne, de las venas, de las entrañas mismas de sus enemigos. Pero ese poder se le desvanece entre sus propias manos ya que el asunto no tiene que ver con lo visceral, sino con lo espiritual. Este extremo se refuerza al despreciar al representante humano de los dioses: el adivino Tiresias. Ya en la versión clásica vemos cómo Creonte afirma de ese mismo personaje: "Es que la raza de los adivinos está toda ella encariñada con el dinero" (Sófocles 183). Y el Creonte de Veloz sostiene que "los adivinos hablan para bien de su cuerpo, para lucro de su estómago" (49). Así pues, el poder terrenal de Creonte se corporiza en la humillación supra-terrenal de Polinices. Pero, de este modo, su justificación como soberano se tambalea, sobrepasando la jurisdicción mundana para intervenir en lo divino. De ahí su pérdida de autoridad; pasando así de soberano a tirano.

Finalmente, esta metamorfosis se justifica además con un listado de defectos propios del déspota clásico, que, no obstante, eran susceptibles de aplicar al propio Trujillo: impiedad, soberbia, crueldad (ADARCO: “ique aún recuerdo el estruendoso ruido de los tuyos decapitando argivos en vez de mantenerlos prisioneros!," 44), ignorancia (SOLDADO PRIMERO: "Creonte, jel soberano de la ignorancia, que osa ofender a los dioses y desconoce el precio de su encono!," 39), tozudez, incluso, falta de dignidad regia (ADARCO: "No son dignas de rey tus palabras; hablas como un cualquiera," 40).

\section{Lo maduro y lo podrido: conclusiones}

Tras este breve recorrido por estas tres obras, nos damos cuenta de cómo los autores, utilizando diversos recursos dramáticos, llegan a la misma conclusión: la sociedad dominicana, en general, y el movimiento contestatario, en particular, se encontraban, en el momento en el que se escriben las piezas, lo suficiente maduros como para exigir un cambio de gobierno, para sacar del cesto a la manzana podrida, emponzoñada más bien. Fijémonos, como más allá de sus limitados séquitos de fieles, los antagonistas de nuestras 
obras se encuentran solos, aislados frente a un colectivo mucho mayor, que se subleva ante su autoridad fálica, que se pretende inamovible. Asimismo, y en lo tocante al final del enemigo del pueblo (Ibsen mediante), percatémonos de cómo los dramaturgos no apuestan por una destrucción física. En cambio, lo dejan vivir para que soporte la humillación de verse derrotado y despreciado. Más que un tiro en la sien duele verse transmutado de verdugo a payaso. ${ }^{6}$

\section{Escuela de Estudios Hispanoamericanos-CSIC (Sevilla, España)}

\section{Notes}

1 En marzo de 2004 apareció su Antología del teatro dominicano contemporáneo, en dos tomos. Allí recoge parte de lo más significativo de esta dramaturgia como pueden ser algunas de las obras de Máximo Avilés Blonda, Franklin Domínguez, Manuel Rueda, Reynaldo Disla, Haffe Serulle, Iván García o Efraim Castillo, entre otros. Sin embargo, aún está por hacer una antología que agrupe a las promociones más recientes, al grupo creciente de dramaturgos que se encuentran en la amplia franja de los 20-50 años.

2 A este drama se refiere Ramón Emilio Reyes cuando dice: "es una tragedia en tres actos que parte de la tragedia Filoctetes de Sófocles, pero Incháustegui lo ubica en la actualidad mediante el uso de detalles modernos así como trasladando la actitud vital a la manera y al gesto del espíritu actual. Materialmente, el escenario sofócleo se presta a la comparación: es una isla, y ruge el mar de igual modo que en esta tragedia actual" (1972: 80).

3 Gerón (2003: 260) hace el siguiente repaso-selección de su producción: El sol y las cosas; El buen ladrón, novela, Colección Arquero, Creonte y seis relatos; Intus, poemas, Colección Brigadas Dominicanas, 1962; El buen ladrón y Judas, novela corta, Colección Pensamiento Dominicano, 1962; La vida no tiene nombre, Colección Testimonio, 1965; Los ángeles de huesos, novela, Colección El Puño; Cultura, teatro y relatos en Santo Domingo, Ediciones de la Universidad Católica Madre y Maestra, Santiago, 1970; De abril en adelante, novela; Sobre cultura dominicana y otras culturas; De dónde vino la gente, novela para niños; Novelas cortas; La palabra reunida, poema; La biografía difusa de Sombra Castañeda, novela, Monte Ávila; La fértil agonía del amor, cuentos; Apearse de la máscara, poemas, Colección Orfeo, 1985; Florbella; Cuentos y reuentos y casicuentos; Poemas de Cierrel Retorno de la palabra; Materia prima; Ritos y cabaret; Panorama histórico de la villa de Santo Domingo, Colección V Centenario, 1994; Villa Francisca y otras fantasías, crónicas, 1996; y Uña y carne, novela, 2000. Añadamos que en 2006 ha conseguido el premio de narrativa José María Arguedas, convocado por Casa de las Américas, con La mosca soldado.

4 Nótese la coincidencia en este punto con el título de Espigas maduras. Es significativo que se utilice el mismo símil para reafirmar que había llegado el momento de derrocar la dictadura, del "non plus ultra" trujillista.

5 Así pues, afirma el Anciano: "La religión está por encima de toda grandeza humana, no es invento de los hombres sino encuentro de éstos con ella en cualquier punto de la tierra" (32).

6 Obviamente, el revuelo censor que habría causado la muerte de los antagonistas habría sido mucho mayor. Por ello, no hemos de descartar esta razón "práctica" a la hora de decantarse por un final más moderado, teniendo en cuenta además que se trata de dramas que optan por sugerir, por la doble lectura, más que por el impulso panfletario. 


\section{Bibliografía}

Bachelard, Gaston. La poética del espacio. México D.F.: Fondo de Cultura Económica, 2005.

Del Valle, Teresa. "El espacio y el tiempo en las relaciones de género." Historia de la Antropología Social: escuelas y corrientes. Ed. Traude Müllauer-Seichter. Madrid: UNED, 2005: 170-92.

Domínguez, Franklin. Teatro: Espigas maduras, Antígona-Humor, Los actores, El encuentro. Santo Domingo: Ediciones de la Sociedad de Autores y Compositores Dramáticos, sin fecha.

Esquilo. TragediaS completas. Madrid: Cátedra, 2003.

Gerón, Cándido. Diccionario de autores dominicanos (1492-2003). Santo Domingo: Editora de Colores, 2003.

Huizinga, Johan. Homo ludens. Madrid: Alianza, 2000.

Incháustegui Cabral, Héctor Santiago. Miedo en un puñado de polvo. Buenos Aires: Américalee, 1964.

Leal, Rine. "Piñera todo teatral." Virgilio Piñera: Teatro completo. La Habana: Letras Cubanas, 2006.

Lockward, Jaime A. Teatro dominicano. Pasado y presente. Ciudad Trujillo: Editorial La Nación, 1959.

Moya Pons, Frank. Manual de historia dominicana. Santo Domingo: Universidad Católica Madre y Maestra, 1981.

Pavis, Patrice. Diccionario del teatro. Barcelona: Paidós, 2002.

Reyes, Ramón Emilio. "El tema universal y la libertad en el teatro dominicano actual." Aula, Revista General de la Universidad Nacional Pedro Henríquez Ureña 1 (1972).

Sánchez, Florencio. Barranca abajo. Madrid: Cátedra, 1997.

Sófocles. Tragedias completas. Madrid: Cátedra, 2004.

Ubersfeld, Anne. Semiótica teatral. Madrid: Cátedra, 1998.

Veloz Maggiolo, Marcio. Creonte. Seis relatos. Santo Domingo: Arquero, 1963. . Cultura, teatro y relatos en Santo Domingo. Santiago de los Caballeros: Universidad Católica Madre y Maestra, 1972. 